\title{
Using Natural Ecology to Predict Higher Cognition in Human and Non-human Primates
}

\begin{abstract}
Bennett L. Schwartz
Department of Psychology, Florida International University

*Corresponding author (Email: schwartb@fiu.edu)

Citation - Schwartz, B. L. (2019). Using natural ecology to predict higher cognition in human and non-human primates. Animal Behavior and Cognition, 6(4), 344-354. https://doi.org/10.26451/abc.06.04.13.2019

Abstract - Many critical aspects of contemporary human cognitive functionality (e.g., reading, fixing a car) evolved historically in a time frame that biological natural selection cannot account for. Because of this, the best way to understand the factors that may have led to human cognition evolution is to look at cognitive processes in nonhuman primates. I argue here that comparative approaches are successful in informing us about human cognitive evolution. Furthermore, making predictions based on natural ecology will allow us to explore comparative cognition in a manner that avoids the trend to determine if non-human primates simply can do what we do. Instead, we can track different patterns of natural selection by examining how cognition differs across specific ecological niches. In this essay, I write of the excellent work applying foraging ecology to spatial memory. I then consider the ways in which metacognition has been addressed in humans and non-human primates and apply the logic of looking for differences based on ecology. Finally, I consider one paradigm that have been used to address the evolution of cognition in humans - survival processing - and discuss how it maps to non-human primates.
\end{abstract}

Keywords - Spatial memory, Metacognition, Natural selection, Survival processing, Non-human primates

We know that human beings evolved - we can see that in the fossil record, we can see it in the record of DNA across human ethnic groups, and we can infer it from observed natural selection in other species. However, many of the factors that influenced the evolution of human cognition remain elusive for a number of reasons. One of the reasons that has received a lot of attention is that the conditions human beings find themselves in now do not resemble at all the conditions that were present during the bulk of human evolution (Barkow, Cosmides, \& Tooby, 1992). This is true both for technology-driven societies and for other groups in our current world, including remaining groups that may still be living 'traditional' lifestyles. Thus, it is difficult to directly relate the ways in which our current environments shape our minds into arguments about how natural selection shaped our minds in the past. Yet, thinking about and trying to derive scientific understandings of the nature of human cognitive evolution is an irresistible topic that many of our most prominent cognitive psychologists have set as the goal of their careers (Boles, 2019; Nairne, 2016; Tooby \& Cosmides, 2016). The view espoused here is that the best way to understand human cognitive evolution is to examine the comparative psychology literature to determine what our nearest relative species can and cannot do, explore what mechanisms may underlie their cognitive abilities, and also to relate their ecological niches to their cognitive abilities (Balda \& Kamil, 1989, 1992; Clayton \& Dickinson, 1999; Hampton, 2019; Krause et al., 2019; Metcalfe \& Jacobs, 2010; Sulikowski \& Burke, 2011). 
In this paper, I consider three paradigms, two drawn from comparative psychology and one from cognitive psychology. These paradigms are 1) Spatial memory and foraging ecology, 2) Metacognition in humans and non-human primates, and) Survival processing: a paradigm currently used to look at the influences of natural selection on human memory, (Krause et al., 2019; Nairne, Cogdill, \& Lehman, 2017; Nairne, Thompson, \& Pandeirada, 2007). My view is that for human cognition researchers to address issues of cognitive evolution, they will need to import methodologies such as those used in the study of spatial memory in non-human species. Ecologically-based hypotheses that emerge from comparative psychology offer the best window into understanding the factors that may have influenced the natural selection of human cognition. Moreover, examining if animals behave like people in some situations (e.g., metacognition) also requires more attention to the natural history of the species involved. Given the extensive ground covered in this paper, I only partially review the literature in each area. Rather, I focus on the strengths and weaknesses of each of these paradigms for thinking about human cognitive evolution.

\section{Spatial Memory and Foraging Ecology}

Within the domain of comparative psychology, the relation of spatial memory to foraging ecology has been widely studied (Sherry, Jacobs, \& Gaulin, 1992; Shettleworth, 2001). Although the focus here is on primate memory, the relation of spatial memory and foraging ecology has been masterfully investigated with respect to memory in bird species (Balda \& Kamil, 1989; 1992; Bugnyar \& Kotrschal, 2002). This research is based on the observation, dating back to Darwin that closely related species (genetically) may occupy different ecological niches (Weiner, 1994). For example, one species may store food, whereas a closely related species may not. One species may eat nuts and fruits, whereas another species eats insects and other small animals. Researchers can then examine changes in memory performance as a function of ecological niche across closely related species. Overall, for example, birds who store food have better spatial memory than birds that do not (e.g., Balda, Olson, Kamil, \& Nims, 1995). Along similar lines, there are some species that are more likely to find more food if they stay in place. Thus, birds that eat tree sap should remain in place once they have access to tree sap, but birds that eat nectar from flowers should move quickly once a food source has been depleted (Healy \& Hurly, 2013). The prediction is that nectar-eaters should learn to move quickly from one location to the next. In an experiment, they should learn faster when they are rewarded for shifting from one spatial location to another, aptly named a win-shift advantage. Sap-eaters should learn more quickly when they are reinforced for staying in place, named a win-stay advantage. In keeping with this, different patterns of success can be seen in win-stay and win-shift paradigms in birds, such as hummingbirds (Healy \& Hurly, 2013) and lorikeets (Sulikowski \& Burke, 2011). This strategy of using foraging ecology to predict memory patterns in birds has been highly successful. It suggests that natural selection has shaped memory in birds. There are some data that suggest foraging ecology also predicts memory patterns in primates (e.g., MacDonald, 1994; MacDonald, Pang, \& Gibeault, 1994; Platt, Brannon, Briese, \& French, 1996). I review the Platt et al. study in detail because it involves direct comparisons across closely-related species based on predictions from foraging ecology differences.

The Platt et al. (1996) study serves as a good example of this strategy. Platt et al. compared two similar species of New World monkeys, golden-lion tamarins (Leontopithecus rosalia) and a similar species, Wied's marmosets (Callithrix kuhli). Platt et al. were interested in differences in win-stay versus win-shift strategy, but first had to consider differences in home range. Both species are neo-tropical species that live in small family groupings. Golden-lion tamarins tend to have larger home ranges than do Wied's marmosets. The diets of both species also overlap. However, the marmosets eat tree gums at a much higher rate than do the tamarins, and the tamarins spend more time foraging for fruit and insects than do the marmosets. This sets up an interesting comparison of the two species in terms of how these differences might translate into memory differences. The marmoset has a diet much higher in tree gums. An animal that relies on sap is motivated to stay in place because of the difficulty in tapping tree gums is accessing them. Once the source is found, however, it can provide continuous calories for much longer 
than it takes for the marmoset to be satiated (nobody has researched how these monkeys' memory works when trees die, and they must learn to search for appropriate trees elsewhere). However, for the tamarin with its diet of fruit and insects, locating a food source means the next food source will be in a new location. It requires a larger home range and more active movement from one place to another. Therefore, a tamarin is motivated to move once it has exploited a food source. This difference in feeding ecology led Platt et al. (1996) to make several hypotheses as to how these very closely related monkey species would differ in terms of the memory abilities.

Platt et al.'s (1996) first experiment focused on how different size ranges might affect spatial memory. The marmosets have smaller ranges that center on specific trees, whereas the tamarins have larger ranges in order to find more fruit sources. Thus, Platt et al. (1996) suspected that the tamarins will have better spatial memory than the marmosets. However, because the marmosets exploit a steady food source that does not move spatially, they may show equivalent or even better spatial memory at short intervals, whereas the tamarins should outperform the marmosets at longer retention intervals. Thus, Platt et al.'s hypotheses about memory performance in the lab derives from differences in the natural ecology of the two species, exactly in the manner that I am arguing is helpful for understanding the origins of human cognition.

Platt et al.'s (1996) actual study consisted of two kinds of memory tests on captive monkeys - a spatial memory test using a radial arm maze, and a spatial memory test using a delayed matching-tosample task, in which the monkeys had to return to a different station after the retention interval in order to receive an award. In both tasks, there was a short retention interval $(5 \mathrm{~min})$ and a long retention interval ( $24 \mathrm{hrs}$ in the radial arm task, $48 \mathrm{hrs}$ in the delayed matching-to-sample task). The question then is: do differences in foraging ecology predict memory performance for the two species. The answer was a definite "yes." On both the radial maze and the delayed matching-to-sample, the marmosets were superior at the shorter retention interval, consistent with their feeding pattern of staying in place. However, at the longer retention interval, the marmosets were at chance, whereas the tamarins continued to perform above chance and significantly better than the marmosets at both tasks.

In a second experiment, Platt et al. (1996) compared the tamarins' and marmosets' ability to do a delayed matching-to-sample task as a win-stay task instead of the win-shift paradigm. In the win-shift task, as used in their first experiment, the monkey must visit the location that is different from the location originally visited in order to be reinforced. In the win-stay version of the task, the monkey should return to the same location as originally visited in order to be reinforced. For marmosets, their natural foraging strategy approximates the win-stay, as tree sap can be regenerated quickly, whereas for the tamarins, their natural foraging strategy approximates the win-shift because their insects once chased will be elsewhere, and fruit, once consumed will not be available at the same location for some time. Thus, all else being equal, foraging ecology predicts that marmosets will do better on win-stay tasks, but tamarins will do better on win-shift tasks. In keeping with the predictions, performance of the marmosets improved to above chance at $24 \mathrm{hrs}$ when they were tested with a win-stay strategy. The tamarins, however, did not show a difference between the two experiments. Overall, the tamarins also still out-performed the marmosets at the longer retention intervals. Thus, the need for a better memory in tamarins overrode differences that might have been caused by preferences for win-stay or win-shift. But for the marmosets, switching the test to win-stay demonstrated a memory capability not seen in the win-shift task, again emphasizing how natural ecology is useful in predicting cognitive performance.

For researchers in comparative psychology, there is nothing special about the Platt et al. (1996) study. This approach has been used across taxa, from corvids to hummingbirds to voles (Balda, \& Kamil, 1989; Balda et al., 1995; Healy \& Hurly, 2004; Okhovat, Berrio, Wallace, Ophir, \& Phelps, 2015). Applying it to non-human primates, however, is less common but many such studies do exist (see Broihanne et al., 2019). Take a moment, however, to think about how it might apply to human cognition. There are many studies, of course, that do compare humans to closely related species, but in most cases, these studies are not directly motivated by hypotheses generated by comparisons of natural ecology. Indeed, as Krause et al. (2019) wrote, "However, the literature on human learning and memory, namely declarative memory, has not been driven by questions about evolution to the extent seen in comparative 
psychology" (p.14). Rather, we compare humans to close relatives, such as chimpanzees or bonobos to determine if those species are capable of something that we do, whether it is language, theory of mind, episodic memory, or metacognition (e.g., see Lewis, Berntsen, \& Call, 2019, for a review of the work on ape episodic memory). The goal in these studies is to determine if such species are cognitively capable of something that we humans do as a matter of course. However, there are seldom studies that take fundamental differences in how humans and chimpanzees approach certain problems and examine the differences from the perspective of how chimpanzees and humans differ in terms of natural ecology. Of course, determining the nature of 'natural human ecology' is a topic fraught with extreme problems, given that no currently-living human lives in conditions that approximate an 'ancestral environment.' However, there are simple dimensions of human behavior, which are not controversial with respect to human natural ecology, that can be compared to closely related species. Let me provide an example.

Consider diet - it is safe to say that there are some generalities that can be made about a typical human diet, as least as it compares to ape's diets. Diet is a topic seldom addressed by cognitive psychologists interested in human memory - it just does not seem relevant. But we can make predictions about primate memory performance, including our own, based on variations in diet across primate species. Whereas it is impossible to deny that there are tremendous cultural differences in what humans eat and how they eat it, it would not be unreasonable to suggest that, by and large, humans are more dependent on animal protein than are chimpanzees, who, in turn, consume more meat than gorillas. Thus, we have three closely-related species that vary in terms of their diet. Therefore, we could look at cognitive differences in relation to diet rather than, for example, theory of mind, metacognition, or episodic memory. With few exceptions (e.g., harvesting scallops or other shellfish), procuring animal protein involves some form of active pursuit on the part of a human (or chimpanzee) predator. However, a gorilla seldom has to be concerned about its meal running away - wild celery does not have that option. Thus, these differences in diet allow us to make hypotheses about comparing human cognition to closely related species that approximates to the work in comparative psychology, as highlighted by the Platt et al. (1996) study. Applied to memory, one might expect gorillas to be relatively more sensitive to stationary objects, given that some food sources, leaves, will be in the same location the following day, and other food sources, such as figs, will be in the same location at longer retention intervals (the next year). However, humans, and to a lesser extent, chimpanzees will be more sensitive to the movement, as humans and chimpanzees have to pursue prey. How might this play out in an actual experiment? One might design a task in which a participant has to remember the location of specific images or symbols in order to receive reinforcement. In a second task, a participant has to remember the specific trajectory of movement in order to receive reinforcement. I hypothesize that humans will show a selective advantage in the task that requires memory of moving objects relative to chimpanzees and especially gorillas. Any human memory advantage will be less pronounced or not present for the stationary 'remember location' task. One could even imagine a 'grocery task' in which the three species have to remember the stationary locations of foods in which gorillas might outperform humans and chimpanzees, even as humans are best at remembering the direction of moving object in the same spatial landscape.

Thus, even a simplified version of human foraging ecology suggests that we should attend to the trajectory of motion of an object in a way that a gorilla might not (especially given that gorillas may be less affected by predation themselves than smaller primates). This ecology-based prediction makes specific comparative predictions about how humans and other apes would perform in a specific test, even one that is not very ecologically valid, such as remembering the trajectory of motion of an arrow on a computer screen. I contrast this way of thinking with the typical ways in which we compare human cognition to other primates, in which we take a form of cognition that humans do (e.g., retrospective memory monitoring) and then determine if a specific species can also do the task (e.g., Suda-King, 2008). The argument here is not that it is not interesting to determine if apes, for example, have metacognition, theory of mind or episodic memory. The argument here is that if the goal is to understand how natural selection affects primate cognition, including our own, comparisons should be made on tasks that can contrast variances in primate ecological niches. One of those domains in which the primary goal of the comparative literature has been to determine if primate performance can match human performance is 
metacognition. In the next section, I briefly review the literature on both human and non-human metacognition and then consider whether using differences in natural ecology can predict outcomes in metacognition and if thinking about differences in natural ecology leads to a better understanding of metacognition.

\section{Metacognition}

Metacognition refers to our experience and knowledge of our own cognition (Flavell, 1979; Nelson \& Narens, 1990; Rhodes, 2016). Metacognition has been extensively and intensively studied by researchers interested in human memory over the last 55 years (for reviews see Hart, 1965; Rhodes \& Taubler, 2011; Undorf \& Zimdahl, 2018). Although the research is incredibly varied, there are a few themes that can be pulled from the human metacognition literature. The first theme concerns the cognitive mechanisms responsible for producing metacognition judgments. The second theme concerns the accuracy or the extent to which metacognition judgments predict actual performance. Finally, the third theme concerns the extent to which people use metacognition judgments to guide their study and retrieval performance. However, with limited exceptions, the comparative literature on metacognition has focused on only one aspect of metacognition and that is whether a particular species of animals shows the ability to make metacognition judgments (see Beran, Smith, Redford, \& Washburn, 2006; Smith \& Church, 2018 for reviews; see Brown, Basile, Templer, \& Hampton, 2019; Ferrigno, Kornell, \& Cantlon, 2017, for exceptions). Because comparative psychologists have to consider lower-level associative explanations before invoking higher cognitive processes, the emphasis of the animal metacognition research agenda has been making the case that animal behavior in their experiments is, in fact, a reflection of metacognition (Smith et al., 1995, Smith, Jackson, \& Church, 2019, this volume). Simply put, there is a disjoint between the research on human metacognition focusing on understanding mechanism and animal metacognition focusing on proof of concept.

Only a handful of primate species have ever been tested for metacognition abilities, and with rare exceptions, most studies focus on one species (rhesus monkeys, Macaca mulatta). In addition to the work on rhesus monkeys (Beran et al., 2006; Ferrigno et al., 2017; Hampton, 2001), the other species studied are baboons (Malassis, Gheusi, \& Fagot, 2015), capuchin monkeys (Beran, Perdue, Church, \& Smith, 2016; Fujita, 2009), and orangutans (Suda-King, 2008). The general consensus from these many studies on monkey (and ape) metacognition is that that the studied species can monitor both ongoing performance in uncertainty monitoring tasks (Smith \& Church, 2018) and do both prospective and retrospective memory monitoring (Ferrigno et al., 2017). Thus, the data suggest that several species of monkeys have some form of metacognition. At one level, this does tell us that the necessary cognitive processes for metacognition are relatively old in the primate evolutionary lineage. But our point here is we still do not know what natural selection processes may have shaped the evolution of metacognition. For that, we need to conduct more direct comparative studies with hypotheses based on natural ecology (see Beran \& Smith, 2011, for related discussion).

I will make just a brief note on information-seeking studies (e.g., Call \& Carpenter, 2004). In these tasks, a tube is baited with food either so that an animal can see it being baited or see the tube baited with food. In another condition, the animal does not have visual (or other equivalent information) as to the location of food. However, in both conditions the animal can look into the tube before extracting the food. Call and his colleagues have shown that most ape species will look into the tube only when they do not already know if food is in there (Call, 2004; Call \& Carpenter, 2004). Similar findings have been found in rhesus monkeys and capuchin monkeys (Beran \& Smith, 2011). Call (2004) argued that this represents a form of metacognition because the primates must know that they do not know in the hidden condition in order to decide to look, and they must know that they do know in conditions in which they have knowledge about the food in order to forgo looking. One advantage to the information-seeking task is that it relies on an ecologically relevant task. However, it is also unclear if one can identify species differences in information-seeking. All primate species tested to date show evidence of informationseeking under uncertainty. I do not know if it would be possible to make comparative predictions of 
differences across species with respect to information-seeking studies. Therefore, in this paper, I will not focus on information-seeking studies.

Human cognitive psychology has arrived at the consensus view that metacognitive judgments result from heuristics that generally correlate with the memory processes that the judgments are intended to predict (Schwartz \& Jemstedt, in press; Undorf \& Zimdahl, 2018). This leads to situations in which metacognition may be illusory. That is, a particular variable, such as fluency, may increase the judgment that an item will be remembered without an actual increase in the probability of memory performance improving (e.g., Rhodes, 2016; Rhodes \& Castel, 2008). In certain extremes, this may lead to the situation in which metacognition judgments serve as a sort of funhouse mirror, as metacognitive judgments increase, memory performance decreases, and as metacognitive judgments decrease, memory performance decreases (Nelson \& Narens, 1990). Indeed, one such situation was identified by Benjamin, Bjork, and Schwartz (1998). Items that were easy to recall while answering general-information questions were then harder to free recall later. However, judgments of learning made during the answering generalinformation questions predicted higher performance for easily answered questions (Paris is the capital of France) than more difficult to answer questions (Dushanbe is the capital of Tajikistan). Thus, in this study, people's metacognition was perversely inaccurate. High judgments were given to items that were poorly remembered, and low judgments were given to items that were well remembered.

Based on the above reasoning, it is important to note that the failure to find metacognitive accuracy in a non-human species may not be the consequence of a lack of metacognition, but just the bad luck of researchers to lock onto a task in which the processes that lead to judgments are not the same as those that lead to successful memory performance. Indeed, Ferrigno et al. (2017) asked if rhesus monkeys also show metacognition illusions. Ferrigno et al. varied stimulus fluency by varying the contrast of stimuli presented to rhesus monkeys. The monkeys were then required to do a visual match-to-sample task. In both prospective and retrospective judgment tasks, the monkeys showed higher confidence for the higher-contrast stimuli, consistent with human responses. However, there was no difference in performance between the higher- and lower-contrast stimuli, also consistent with human responses. From other studies, we know that rhesus monkeys are capable of metacognitive monitoring (Beran et al., 2006; Hampton, 2001; Kornell, Son, \& Terrace, 2007). Therefore, Ferrigno et al. concluded that rhesus monkeys also show metacognitive illusions.

The current goal is to make predictions about how different primate species will engage metacognition in different ways based on some aspect of their natural ecology (for a related rationale, see Smith \& Church, 2018). This will provide testable comparative predictions, go beyond the 'proof of concept' approach to animal metacognition, and may also allow us to do better at speculating how and why metacognition was selected for. Using the logic developed in the Platt et al. (1996) experiment, we can think about how metacognition control might work across different closely related primate species. Consider sexual migratory patterns, an aspect of natural ecology about which primate species differ. In chimpanzees, males stay in the natal groups, and females migrate to new groups (Emlen \& Oring, 1977). In contrast, in capuchin monkeys, it is the females that stay put, and the males migrate to new groups (Jack \& Fedigan, 2004). A male chimpanzee and a female capuchin monkey will have less new social information to learn than a female chimpanzee and a male capuchin monkey. Thus, it becomes more important for female chimpanzees and male capuchin monkeys to monitor their knowledge of new conspecifics than it is for male chimpanzees and female capuchin monkeys because the female chimpanzees and male capuchin monkeys must learn to recognize new group conspecifics and learn their individual differences, which may have consequences in terms of alliance formation. Therefore, in a task in which these two species must bet on their knowledge of faces, it can be expected that female chimpanzees and male capuchin monkeys will show monitoring and control advantages for faces of conspecifics relative to male chimpanzees and female capuchin monkeys. However, within each species, one might not expect male/female differences for other materials (such as whether novel fruits are edible). If such an experiment turned out to follow the predictions from migratory patterns, it might suggest that natural selection chose for primates who were better able to learn new individuals and know that they have learned. Female chimpanzees and male capuchin monkeys should show more accurate judgments for 
information relevant to migratory patterns, whereas female chimpanzees and male capuchin monkeys would not show such advantages for information irrelevant to migratory patterns. Such ecologically-based hypotheses would bring greater clarity to why we have metacognition and what factors might cause it to change. Outcomes of such studies could then be used to predict patterns of metacognition in species not yet tested. Such a view then places metacognition in non-human primates in such a way as we can make predictions across species concerning which species will show metacognition under what circumstances. To reiterate, the comparative approach based on behavioral ecology will provide us with better insight into how such processes evolved in our own species.

\section{Survival Processing}

Survival processing has become a general term to refer to an encoding strategy in which people consider a list of presented words in terms of their usefulness to survival, usually in an "ancestral" grassland (Nairne \& Pandeirada, 2010). Research has shown that survival processing leads to better free recall than a wide variety of other encoding techniques (see Scofield, Buchanan, \& Kostic, 2018; Tay, Jonason, Li, \& Ching, 2019, for reviews). Although most of the research now focuses on the proximate mechanisms that produce survival processing advantages across a range of memory tests, the original goal of developing the paradigm was to demonstrate that issues of natural selection could have strong and measurable effects on current human cognition (e.g., Nairne, Coverdale, \& Pandeirada, 2019). Although the evidence for a survival processing advantage in memory is strong, I remain skeptical about the utility of thinking about this effect in terms of human natural selection (also see Krause et al., 2019; Sandry, Trafimow, Marks, \& Rice, 2013). First, one can generate explanations that have nothing to do with natural selection that would center on increases in attention when survival is on the line. Second, and more relevant here, given the highly verbal nature of the task, it is difficult to think about how survival processing would work in a comparative analysis across closely related primate species.

In a typical survival processing paradigm, human participants are given different instructions concerning how to encode a list of unrelated words for later free recall (Nairne \& Pandeirada, 2010). In the survival condition, people are told to imagine themselves on the grasslands of a foreign land and then to evaluate the objects that the words represent in terms of their usefulness to survival. In one control condition used, people are be told to imagine that they are moving to a foreign land and to evaluate the objects that the words represent in terms of their usefulness in terms of the move (e.g., Nairne \& Pandeirada, 2010). Regardless of the control condition used, people free recall more words from the ancestral-survival condition than other conditions (Scofield et al., 2018). According to Nairne and Pandeirada (2010), invoking survival in ancestral conditions capitalizes on 'ancestral priorities' (p. 3). As such, in their view, evolutionary theory predicts that people will recall more target words from the survival condition than from control conditions. Indeed, the ancestral-survival condition has been shown to produce better free recall of unrelated words across many studies now (Scofield et al., 2018). Moreover, many researchers have explored the proximal mechanism that humans use in the ancestralsurvival condition that they do not use in control conditions (Kazanas \& Altarriba, 2017). All in all, this research has been enormously successful in exploring the nature of human memory, and the survival processing effect is replicable and robust.

Then why is it being criticized here? I criticize this paradigm here for several reasons. First, to advance the themes articulated in this paper, it is unclear how this task actually maps onto ancestral priorities. That is, it is doubtful that actual humans 40,000 years ago were explicitly engaged in assessing objects for their contribution to their own survival. More likely, people saw a tasty tuber, assessed it as edible, and then picked it. They were not consciously assessing survival to any greater extent than we do today when we choose the Nissan GTR over the safer Nissan Altima at a car showroom. Second, the advantage of survival processing over other encoding strategies is robust and highly replicable when the criterion test is free recall, but less so when other tests are used such as cued recall (e.g., Schwartz \& Brothers, 2014). Third, there appear to be no interactions with other evolutionarily-relevant variables. For example, Krause et al. (2019) did not find any interactions of survival-processing instructions with kin- 
selection instructions. That is, helping close relatives survive did not lead to better free recall than helping unrelated strangers survive. If natural selection had influenced this effect, one might also expect an interaction with age- kin selection effects should get bigger with age, whereas survival processing effects should diminish with age. However, the data are not supportive here either (see Nouchi, 2012). Given that all organisms need to survive in order to impact natural selection, one would expect to see advantages of survival processing everywhere - in all aspects of human cognition. That it does not occur in all areas suggests that the proximal mechanism underlying survival processing may derive from something other than the 'need to survive.' Finally, such a task does not lend itself to comparative analysis. How could one effectively do survival-processing task with a chimpanzee, let alone a marmoset? First, this prevents some methodological challenges. All species must survive in order to advance their natural selection. As such, one would expect survival-processing effects in all species, if it were possible to create comparable scenarios for other species. This suggests that one cannot really do comparative studies as it is hard to imagine a species that would not show survival-processing effects if tested properly, provided it has some memory capacity. Therefore, survival processing effects, however robust, are not the kind of tasks that allow us to look at differences in cognitive processes across difference in ecology.

\section{Conclusions}

There are few bigger questions in cognitive science than how human cognition and memory evolved to be the complex system that human beings rely on today. However, addressing the issue of how cognition evolved is fraught with problems - methodologically, statistically, and ethically (Powell, Mikhalevich, Logan, \& Clayton, 2017). To address the ways in which we can use ancestral priorities to probe current behavioral patterns and thereby look for what variables might have been relevant to evolution (e.g., Krause et al., 2019; Nairne et al., 2019). This includes both examining the survival processing effect and exploring how animacy influences memory performance (VanArsdall, Nairne, Pandeirada, \& Cogdill, 2017). Instead, I offer the model of comparative psychology in which we make theories based on known ecological differences and determine how those differences affect behavior in cognitive experiments. To the extent that humans show differences from other primates based on known differences in such things as foraging ecology, predator detection and avoidance, sexual dimorphism, to name a few, then we just might be able to infer something about the patterns that led to human cognitive evolution. In this paper, I suggest two such specific paradigms. First, that we can use differences in meat consumption and hunting behavior to predict differences in memory for stationary and moving objects. Second, I predict that patterns of out-migration across primate species can be used to predict face memory and metacognitive control of learning new faces. My assertion here is that comparing humans to other primates in tasks that more directly follow from differences in ecology will better help us understand the nature of human cognitive evolution.

\section{References}

Balda, R. P., \& Kamil, A. C. (1989). A comparative study of cache recovery by three corvid species. Animal Behaviour, 38, 486-495.

Balda, R. P., \& Kamil, A. C. (1992). Long-term spatial memory in Clark's nutcracker, Nucifraga columbiana. Animal Behaviour, 44, 761-769.

Balda, R. P., Olson, D. J., Kamil, A. C., \& Nims, P. J. (1995). Performance of four seed-caching corvid species in operant tests of nonspatial and spatial memory. Journal of Comparative Psychology, 109, 173-181.

Barkow, J., Cosmides, L. \& Tooby, J. (1992). The adapted mind: Evolutionary psychology and the generation of culture. New York, NY: Oxford University Press.

Benjamin, A. S., Bjork, R. A., \& Schwartz, B. L. (1998). The mismeasure of memory: When retrieval fluency is misleading as a metamnemonic index. Journal of Experimental Psychology: General, 127, 55-68.

Beran, M. J., Perdue, B. M., Church, B. A., \& Smith, J. D. (2016). Capuchin monkeys (Cebus apella) modulate their use of an uncertainty response depending on risk. Journal of Experimental Psychology: Animal Learning and Cognition, 42, 32-43. 
Beran, M. J., \& Smith, J. D. (2011). Information seeking by rhesus monkeys (Macaca mulatta) and capuchin monkeys (Cebus apella). Cognition, 120, 90-105.

Beran M. J., Smith J. D., Redford J. S., \& Washburn. D. A. (2006) Rhesus macaques (Macaca mulatta) monitor uncertainty during numerosity judgments. Journal of Experimental Psychology: Animal Behavior Processes, 32, $111-119$.

Boles, D. B. (2019). Cognitive evolution. Oxon, England: Routledge.

Broihanne, M-H., Romain, A., Call, J., Thierry, B., Wascher, C. A. F., De Marco, A.,...Dufour, V. (2019). Monkeys (Sapajus apella and Macaca tonkeana) and great apes (Gorilla gorilla, Pongo pygmaeus, Pongo abelii, Pan paniscus, and Pan troglodytes) play for the highest bid. Journal of Comparative Psychology, 133, 301-312.

Brown, E. K., Basile, B. M., Templer, V. L., \& Hampton, R. R. (2019). Dissociation of memory signals for metamemory in rhesus monkeys (Macaca mulatta). Animal Cognition, 22, 331-341.

Bugnyar, T., \& Kotrschal, K. (2002). Observational spatial learning and the raiding of food caches in ravens, Corvus corax: Is it tactical deception? Animal Behaviour, 64, 185-195.

Call, J. (2004). Inferences about the location of food in the great apes (Pan paniscus, Pan troglodytes, Gorilla gorilla, and Pongo pygmaeus). Journal of Comparative Psychology, 118, 232-241.

Call, J., \& Carpenter, M. (2004). Do apes and children know what they have seen? Animal Cognition, 4, 207-220.

Clayton, N. S., \& Dickinson, A. (1999). Memory for the contents of caches by scrub jays. Journal of Experimental Psychology: Animal Behavior Processes, 25, 82-91.

Emlen, S. T., \& Oring, L.W. (1977). Ecology, sexual selection, and the evolution of mating systems. Science, 197, 215-223.

Ferrigno, S., Kornell, N., \& Cantlon, J. F. (2017). A metacognitive illusion in monkeys. Proceedings of the Royal Society of Britain, 284, 1862, 20171541.

Flavell, J. H. (1979). Metacognition and cognitive monitoring-A new era of cognitive-developmental inquiry. American Psychologist, 34, 906-911.

Fujita, K. (2009). Metamemory in tufted capuchin monkeys (Cebus apella). Animal Cognition, 12, 575-585.

Hampton, R. R. (2001). Rhesus monkeys know when they remember. Proceedings of the National Academy of Sciences, USA, 98, 5359-5362.

Hampton, R. (2019). Parallel overinterpretation of behavior of apes and corvids. Learning and Behavior, 47, $105-106$.

Hart, J. T. (1965). Memory and the feeling-of-knowing experience. Journal of Educational Psychology, 56, 208216.

Healy, S. D., \& Hurly, T. A. (2004). Spatial learning and memory in birds. Brain Behavior and Evolution, 63, 211220.

Healy, S. D. \& Hurly, T. A. (2013). What hummingbirds can tell us about cognition in the wild. Comparative Cognition and Behavior Reviews, 8, 13-28.

Jack, K., \& Fedigan, L. (2004). Male dispersal patterns in white-faced capuchins, Cebus capucinus. Part 2: Patterns and causes of secondary dispersal. Animal Behaviour, 67, 771-782.

Kazanas, S. A., \& Altarriba, J. (2017). Did our ancestors fear the unknown? The role of predation in the survival advantage. Evolutionary Behavioral Sciences, 11, 83-91.

Kornell, N., Son, L. K., \& Terrace, H. (2007). Transfer of metacognitive skills and hints seeking in monkeys. Psychological Science, 18, 64-71.

Krause, M. A., Trevino, S., Cripps, A., Chilton, K., Sower, E., \& Taylor, J. P. (2019). Inclusive fitness does not impact the survival processing effect. Animal Behavior and Cognition, 6, 13-31.

Lewis, A., Berntsen, D., \& Call, J. (2019). Long-term memory of past events in great apes. Current Directions in Psychological Science, 28, 117-123.

MacDonald, S. E. (1994). Gorilla's (Gorilla gorilla gorilla) spatial memory in a foraging task. Journal of Comparative Psychology, 108, 107-113.

MacDonald, S. E., Pang, J. C., \& Gibeault, S. (1994). Marmoset (Callithrix jacchus jacchus) spatial memory in a foraging task: Win-stay versus win-shift strategies. Journal of Comparative Psychology, 108, 328-334.

Malassis, R., Gheusi, G., \& Fagot, J. (2015). Assessment of metacognitive monitoring and control in baboons (Papio papio). Animal Cognition, 17, 1347-1362.

Metcalfe, J. \& Jacobs, W. J. (2010). People's study time allocation and its relation to animal foraging. Behavioral Processes, 83, 213-221.

Nairne, J. S. (2016). Adaptive memory: Fitness-relevant "tunings" help drive learning and remembering. In C. D. 
Geary, \& B. D. Berch (Eds.), Evolutionary perspectives on child development and education, (pp. 251269). New York, NY: Springer International.

Nairne, J. S., Cogdill, M., \& Lehman, M. (2017). Adaptive memory: Temporal, semantic, and rating-based clustering following survival processing. Journal of Memory and Language, 93, 304-314.

Nairne, J. S., Coverdale, M. E., \& Pandeirada, J. N. S. (2019). Adaptive memory: The mnemonic power of survival-based generation. Journal of Experimental Psychology: Learning, Memory, and Cognition. Advanced online publication.

Nairne, J. S., \& Pandeirada, J. N. S. (2010). Adaptive memory: Ancestral priorities and the mnemonic value of survival processing. Cognitive Psychology, 61, 1-22.

Nairne, J. S., Thompson, S. R., \& Pandeirada, J. N. S. (2007). Adaptive memory: Survival processing enhances retention. Journal of Experimental Psychology: Learning, Memory, \& Cognition, 33, 263-273.

Nelson, T. O., \& Narens, L. (1990). Metacognition: A theoretical framework and new findings. In G. H. Bower (Ed.), The psychology of learning and motivation: Advances in research and theory (Vol. 26, pp. 125-173). San Diego: Academic Press.

Nouchi, R. (2012). The effect of aging on the memory enhancement of the survival judgment task. Japanese Psychological Research, 54, 210 - 217.

Okhovat, M., Berrio, A., Wallace, G., Ophir, A. G., \& Phelps, S. M. (2015). Sexual fidelity trade-offs promote regulatory variation in the prairie vole brain. Science, 350, 1371- 1374.

Olson, D. J., Kamil, A. C., Balda, R. P., \& Nims, P. J. (1995). Performance of four-seed caching corvid species in operant tests of nonspatial and spatial memory. Journal of Comparative Psychology, 109, 173-181.

Platt, M. L., Brannon, E. M., Briese, T. L., \& French, J. A. (1996). Differences in feeding ecology predict differences in performance between golden lion tamarins (Leontopithecus rosalia) and Wied's marmosets (Callithrix kuhli) on spatial and visual memory tasks. Animal Learning and Behavior, 24, $384-393$.

Powell, R., Mikhalevich, I., Logan, C., \& Clayton, N. S. (2017). Convergent minds: The evolution of cognitive complexity in nature. Interface Focus, 7, 20170029.

Rhodes, M. G. (2016). Judgments of learning: Methods, data, and theory. In J. Dunlosky \& S. Tauber (Eds.), The Oxford handbook of metacognition (pp. 65-80). New York: Oxford University Press.

Rhodes, M. G., \& Castel, A. D. (2008). Memory predictions are influenced by perceptual information: Evidence for metacognitive illusions. Journal of Experimental Psychology: General, 137, 615-625.

Rhodes, M. G., \& Tauber, S. K. (2011). The influence of delaying judgements of learning (JOLs) on metacognitive accuracy: A meta-analytic review. Psychological Bulletin, 137, 131-148.

Sandry, J., Trafimow, D., Marks, M. J., \& Rice, S. (2013). Adaptive memory: Evaluating alternative forms of fitness-relevant processing in the survival processing paradigm. PLOS One, 8, e60868.

Schwartz, B. L., \& Brothers, B. R. (2014). Survival processing and paired-associate learning. In B. Schwartz, M. L. Howe, M. P. Toglia, \& H. Otgaar (Eds). What is adaptive about adaptive memory? (pp.159-181). New York, NY: Oxford University Press.

Schwartz, B. L., \& Jemstedt, A. (in press). The role of fluency and dysfluency in metacognitive experiences. In P. Metallidou \& D. Moraitou (Eds.), Trends and prospects in metacognition research across the lifespan - a tribute to Anastasia Efklides. New York, NY: Springer.

Scofield, J. E., Buchanan, E. M, \& Kostic, B. (2018). A meta-analysis of the survival-processing advantage in memory. Psychonomic Bulletin \& Review, 25, $997-1012$.

Shettleworth, S. J. (2001). Animal cognition and animal behaviour. Animal Behavior, 61, 277-286.

Sherry, D. F., Jacobs, L. F. \& Gaulin, S. J. (1992). Spatial memory and adaptive specialization of the hippocampus. Trends in Neuroscience, 15, 298-303.

Smith, J. D., \& Church, B. A. (2018). Dissociable learning processes in comparative psychology. Psychonomic Bulletin and Review, 25, 1565-1584.

Smith, J. D., Jackson, B. N., \& Church, B. A. (2019). The cognitive architecture of uncertainty. Animal Behavior and Cognition, 6, 236-246.

Smith, J. D., Schull, J., Strote, J., McGee, K., Egnor, R., \& Erb, L. (1995). The uncertain response in the bottlenosed dolphin (Tursiops truncatus). Journal of Experimental Psychology: General, 124, 391-408.

Suda-King, C. (2008). Do orangutans (Pongo pygmaeus) know when they do not remember? Animal Cognition, 11, 21-42.

Sulikowski, D., \& Burke, D. (2011). Win-shift and win-stay learning in the rainbow lorikeet (Trichoglossus haematodus). Journal of Comparative Psychology, 125, 143 - 149.

Tay, P. K.C., Jonason, P. K, Li, N.P., \& Ching, G. H-L. (2019). Is memory enhanced by the context or survival 
threats? A quantitative and qualitative review on the survival processing paradigm. Evolutionary Behavioral Sciences, 13, $31-54$.

Tooby, J. \& Cosmides, L. (2016). The theoretical foundations of evolutionary psychology. In D. M. Buss (Ed.), The handbook of evolutionary psychology, Second ed., Vol 1: Foundations. (pp. 3-87). Hoboken, NJ: John Wiley \& Sons.

Undorf, M., \& Zimdahl, M. F. (2018). Metacognition and memory for a wide range of font sizes: What is the contribution of perceptual fluency? Journal of Experimental Psychology: Learning, Memory, and Cognition, 45, 97-109.

VanArsdall, J. E., Nairne, J. S., Pandeirada, J. N. S, \& Cogdill, M. (2017). A categorical recall strategy does not explain animacy effects in episodic memory. The Quarterly Journal of Experimental Psychology, 70, 761 771.

Weiner, J. (1994). The beak of the finch: A story of evolution in our time. New York: Knopf. 